\title{
Photoelectrocatalytic biosynthesis fueled by microplastics
}

\author{
Jinhyun Kim, ${ }^{1}$ Jinha Jang, ${ }^{1}$ Thomas Hilberath, ${ }^{2}$ Frank Hollmann, ${ }^{2}$ and Chan Beum Park ${ }^{1 *}$ \\ ${ }^{1}$ Department of Materials Science and Engineering, Korea Advanced Institute of Science and \\ Technology (KAIST), 335 Science Road, Daejeon 305-701, Republic of Korea \\ ${ }^{2}$ Department of Biotechnology, Delft University of Technology, Van der Maasweg 9, 2629 HZ Delft, \\ Netherlands*Email: parkcb@kaist.ac.kr
}

\begin{abstract}
Biocatalytic artificial photosynthesis integrates photocatalysis and redox biocatalysis through inspiration from plants to synthesize value-added chemicals using solar energy. The nature-inspired approach, however, suffers from sluggish rates due to the challenging water oxidation kinetics. Here, we report photoelectrochemical (PEC) biosynthetic reactions that use nonrecyclable real-world PET microplastics as an electron feedstock. A Zr-doped hematite photoanode (i) extracts electrons from hydrolyzed PET solutions obtained from post-consumer PET wastes (e.g., drinking bottles) and (ii) transfers the electrons to the bioelectrocatalytic site. Carbon-based cathodes receive the electrons to (i) activate redox enzymes [e.g., unspecific peroxygenase (UPO), L-glutamate dehydrogenase (GDH), ene-reductase from the old yellow enzyme family (OYE)] and (ii) drive various organic synthetic reactions, such as oxyfunctionalization of $\mathrm{C}-\mathrm{H}$ bonds, amination of $\mathrm{C}=\mathrm{O}$ bonds, and asymmetric hydrogenation of $\mathrm{C}=\mathrm{C}$ bonds. These photoelectrocatalyst/biocatalyst hybrids achieve benchmark total turnover numbers of 362,000 (UPO), 144,000 (GDH), and 1,300 (OYE). This work presents a photoelectrocatalytic approach for integrating environmental remediation and biocatalytic photosynthesis towards sustainable solar-to-chemical synthesis.
\end{abstract}




\section{Introduction}

Plastics have become indispensable in our modern life; approximately 390 million tons of the polymers are produced worldwide annually. ${ }^{1}$ The recent outbreak of the coronavirus pandemic has further stimulated global demand for plastics because of the increased usage of packaging materials and personal protective equipment. ${ }^{2}$ The majority of plastic wastes have been incinerated or accumulated in landfills or the natural environment, ${ }^{1}$ representing a severe loss of valuable resources (e.g., annual hemorrhage of 80 to 120 billion dollars to global economy)., ${ }^{3,4}$ Furthermore, microplastics-defined as plastics smaller than $5 \mathrm{~mm}$ - are imposing serious ecological and environmental threats. ${ }^{1,5}$ Microplastics originate from the direct input from a variety of products (e.g., cosmetic beads, clothing fibers) or the degradation of plastic debris in the marine environment. Their small size and dilution hinder proper collection and reuse of microplastics, making them ubiquitous in oceans and even drinking water. ${ }^{6}$

Plastic recycling is desirable to address the issue but its execution is challenging because of mediocre waste management, deficiency of problem recognition, and complex chemical makeup.,4 For example, approximately $50 \%$ of poly(ethylene terephthalate) (PET) is not collected for recycling, although PET is the most abundant polyester plastic with an annual production of 38 million tons globally for textiles and packaging. ${ }^{1}$ Only $7 \%$ of PET bottles are remolded into bottles, but recycling PET is still hampered by the loss of mechanical properties during the recycling process. ${ }^{7}$ Chemical recycling has been considered as an alternative approach to convert nonrecyclable plastic wastes into valuable chemicals and materials. ${ }^{3}$

Here, we report a solar-driven biocatalytic photoelectrochemical (PEC) platform using nonrecyclable real-world PET microplastics as an electron feedstock to synthesize value-added compounds through the synergistic coupling of photoelectrocatalysis and redox biotransformations, 
including oxyfunctionalization of $\mathrm{C}-\mathrm{H}$ bonds, reductive amination of $\mathrm{C}=\mathrm{O}$ bonds and transhydrogenation of conjugated $\mathrm{C}=\mathrm{C}$ bonds. As depicted in Fig. 1, the biocatalytic PEC system consists of three components: (i) a zirconium-doped hematite $\left(\mathrm{Zr}: \alpha-\mathrm{Fe}_{2} \mathrm{O}_{3}\right)$ photoanode to extract electrons from hydrolyzed PET solutions (from post-consumer commercial PET wastes from Starbucks and Coca-Cola companies), (ii) a carbon fiber paper (CFP) or anthraquinone-2-carboxylic acid (AQC)anchored CFP cathode to generate 1,4-dihydronicotinamide adenine dinucleotide (1,4-NADH) or $\mathrm{H}_{2} \mathrm{O}_{2}$, respectively, and (iii) a redox enzyme [e.g., NADH-dependent L-glutamate dehydrogenase $(\mathrm{GDH}), \mathrm{NADH}-d e p e n d e n t$ ene-reductase from the old yellow enzyme family $(\mathrm{OYE}), \mathrm{H}_{2} \mathrm{O}_{2}$ dependent unspecific peroxygenase (UPO)] to drive synthetic reactions. The $\mathrm{Zr}: \alpha-\mathrm{Fe}_{2} \mathrm{O}_{3} \mid \mathrm{CFP}-\mathrm{based}$ systems exhibit a broad applicability to other enzymatic substrates and high total turnover numbers (TTNs) of enzymes of 362,000 (UPO), 144,000 (GDH), and 1,300 (OYE), surpassing those of stateof-the-art biocatalytic PEC systems using water as an electron feedstock.

\section{Results}

\subsection{Electrocatalytic reduction of antraquinone for biocatalytic oxyfunctionalization}

We tested a CFP electrode for reductive activation of redox enzymes. The rationale of selecting CFP was its high electrical conductivity, large surface area, high chemical stability and good mechanical strength. ${ }^{8}$ The CFP electrode exhibited randomly oriented microfibers with carbon-based functional groups (e.g., conjugated $\mathrm{C}=\mathrm{C}, \mathrm{C}-\mathrm{C}, \mathrm{C}-\mathrm{OH}$, and $\mathrm{COOH}$ ). In depth structural characterization via

scanning electron microscopy (SEM), X-ray photoelectron spectroscopy (XPS) and Raman spectroscopy are shown in Supplementary Information (Supplementary Fig. 1).

For the electrocatalytic production of $\mathrm{H}_{2} \mathrm{O}_{2}$, we prepared an AQC/CFP electrode via a solution immersion process (see the details in Methods section). The redox behavior of AQC on the 
CFP was confirmed using cyclic voltammetry (CV) under reaction conditions representative for peroxygenase reactions ${ }^{9}[100 \mathrm{mM}$ potassium phosphate (KPi) buffer, $\mathrm{pH}$ 6.0]. The AQC/CFP exhibited a redox wave with a formal potential of $c a .0 .1 \mathrm{~V}$ vs. reversible hydrogen electrode (VRHE) under Ar-enriched environments, whereas the bare CFP did not show the characteristic redox peak (Fig. 2a). We attribute the wave to a typical two-electron-two-proton reduction/oxidation ${ }^{10}$ of $\mathrm{AQC} / \mathrm{AQCH}_{2}$. The surface concentration of $\mathrm{AQC}$ was estimated to be $18 \mathrm{nmol} \mathrm{cm}^{-2}$ from its cyclic voltammogram. Upon purging the electrolyte solution with $\mathrm{O}_{2}$, the cathodic current of the AQC/CFP was much higher than that of the $\mathrm{CFP}$ (Fig. 2a), indicating reoxidation of $\mathrm{AQCH}_{2} \mathrm{via}_{2} \mathrm{O}_{2}$ reduction.

We confirmed the role of $A Q C$ in promoting the reduction of $\mathrm{O}_{2}$ to $\mathrm{H}_{2} \mathrm{O}_{2}$. As shown in Fig. 2b, the rate of $\mathrm{H}_{2} \mathrm{O}_{2}$ production in the AQC/CFP system was $1.85 \pm 0.07 \mathrm{mM} \mathrm{h}^{-1}$ at $0.16 \mathrm{~V}_{\text {RHE. The }}$ rate decreased to $0.90 \pm 0.04 \mathrm{mM} \mathrm{h}^{-1}$ in the absence of AQC. We attribute to the different rates of $\mathrm{H}_{2} \mathrm{O}_{2}$ generation to AQC-driven facilitation of the interfacial electron transfer process; our electrochemical impedance spectroscopic analysis shows that the charge transfer resistance of $\mathrm{AQC} / \mathrm{CFP}$ is lower than that of CFP under $\mathrm{O}_{2}$-rich conditions (Supplementary Fig. 2 and Supplementary Table 1). Under anaerobic conditions, $\mathrm{H}_{2} \mathrm{O}_{2}$ formation was negligible $(<0.06 \mathrm{mM}$ $\mathrm{h}^{-1}$ ) (Supplementary Fig. 3). We further confirmed that AQC/CFP-driven formation of $\mathrm{H}_{2} \mathrm{O}_{2}$ proceeds via a two-step, single-electron reduction of $\mathrm{O}_{2}$ (Supplementary Fig. 4).

Having demonstrated in situ $\mathrm{H}_{2} \mathrm{O}_{2}$ production by the AQC/CFP cathode, we advanced to coupling AQC/CFP-driven electrocatalysis with peroxygenase-catalyzed oxyfunctionalization reactions. We selected the recombinant, evolved peroxygenase from Agrocybe aegerita (rAaeUPO), which exhibits a high activity towards oxidation of $\mathrm{C}-\mathrm{H}$ bonds ${ }^{11}$. Selective oxyfunctionalization reactions of non-activated $\mathrm{C}-\mathrm{H}$ bonds are very challenging in synthetic chemistry because of the kinetically inert nature of $\mathrm{C}-\mathrm{H}$ bonds; ${ }^{11}$ peroxygenases represent promising catalysts for challenging 
oxyfunctionalization reactions because they combine high catalytic activity with high selectivity while depending on simple $\mathrm{H}_{2} \mathrm{O}_{2}$ only as oxidant. The application of $0.16 \mathrm{~V}_{\mathrm{RHE}}$ to $\mathrm{AQC} / \mathrm{CFP}$ cathode drove hydroxylation of ethylbenzene to enantiopure $(R)-1$-phenylethanol [enantiomeric excess (ee) $>99 \%$ ] with a formation rate of $1.63 \pm 0.08 \mathrm{mM} \mathrm{h}^{-1}$, corresponding to a turnover frequency of $\mathrm{r}$ AaeUPO (TOF $\left.\mathrm{T}_{\mathrm{r} a e \mathrm{UPO}}\right)$ of $32,700 \pm 1,500 \mathrm{~h}^{-1}$ (Fig. 2c). Control experiments in the absence of rAaeUPO, substrate, or electrical bias did not produce the enzymatic product (Fig. 2c).

\subsection{Electrocatalytic regeneration of NADH for enzymatic amination and hydrogenation}

We examined electrocatalytic capability of CFP to regenerate enzymatically active 1,4-NADH from $\mathrm{NAD}^{+}$. $\left[\mathrm{Cp}^{*} \mathrm{Rh}(\mathrm{bpy}) \mathrm{H}_{2} \mathrm{O}\right]^{2+}\left(\mathbf{M}_{\mathbf{o x}}, \mathrm{Cp}^{*}=\mathrm{C}_{5} \mathrm{Me}\right.$, bpy $=2,2^{\prime}$-bipyridine $)$ was used as a regeneration catalyst to attain highly regioselective reduction of $\mathrm{NAD}^{+}$into $1,4-\mathrm{NADH}$ according to the literature. ${ }^{12}$ Our linear sweep voltammograms showed a cathodic current of $\mathbf{M}_{\mathbf{o x}}$ in an $\mathrm{O}_{2}$-depleted sodium phosphate $(\mathrm{NaPi})$ buffer $\left(100 \mathrm{mM}, \mathrm{pH}\right.$ 7.5) (Fig. 2d). The addition of $\mathrm{NAD}^{+}$further increased the cathodic current, indicating a catalytic effect of $\mathbf{M}$ in the electron transfer from CFP to $\mathrm{NAD}^{+}$. However, the CFP cathode did not generate cathodic current by $\mathrm{NAD}^{+}$without $\mathbf{M}_{\mathbf{o x}}$ (Supplementary Fig. 5), indicating imperceptible direct reduction of $\mathrm{NAD}^{+}$. We further confirmed CFP-driven conversion of $\mathrm{NAD}^{+}$to $1,4-\mathrm{NADH}$ using $\mathbf{M}_{\mathbf{o x}}$; our ${ }^{1} \mathrm{H}$ nuclear magnetic resonance (NMR) spectra exhibits a NADH's characteristic peak at 6.94 parts per million when we performed controlled potential electrolysis at $-0.2 V_{\text {RHE }}$ (Fig. 2e and Supplementary Fig. 6). The rate of $\mathrm{NADH}$ production was $1.19 \pm 0.07 \mathrm{mM} \mathrm{h}^{-1}$ at the electrical bias, which we estimated using UV-Vis spectroscopy. Control experiments in the absence of $\mathbf{M}_{\mathbf{o x}}, \mathrm{NAD}^{+}$, or electrical bias did not produce NADH (Fig. 2f). 
We applied the electrocatalytic regeneration system to activate GDH from bovine liver; GDH has been reported to receive electrons from NADH for the reductive amination reaction of $\alpha$ ketoglutarate to L-glutamate ${ }^{13}$, which is a global food flavor enhancer ${ }^{14}$, a crop protection agent ${ }^{15}$, and a livestock nutrient ${ }^{16}$. As shown in Fig. 2g, L-glutamate was formed with a rate of $2.74 \pm 0.11$ $\mathrm{mM} \mathrm{h}^{-1}$ and a TOF $\mathrm{GDH}_{\text {of }} 3,900 \pm 200 \mathrm{~h}^{-1}$ at $-0.2 \mathrm{~V}_{\mathrm{RHE}}$; the rate of enzymatic reaction was higher than those of NADH formation reaction (Fig. 2f), which has been observed in reports ${ }^{13,17,18}$ on GDH catalysis driven by NADH regeneration. We may attribute it to faster regeneration of NADH driven by NADH-consuming GDH. The omission of $\mathbf{M}_{\mathbf{o x}}, \mathrm{NAD}^{+}$, or GDH resulted in a negligible amount of L-glutamate (Fig. 2g), which indicates the electron transport from CFP to GDH through NADH regeneration process.

Furthermore, we revealed general applicability of the NADH regeneration system by coupling it with OYE-driven asymmetric hydrogenation reactions. In this experiment, we used an OYE from Thermus scotoductus (TsOYE), catalyzing the enantioselective trans-hydrogenation of $\mathrm{C}=\mathrm{C}$ bonds ${ }^{19,20}$. In addition, we replaced a NaPi buffer with a triethanolamine-buffered solution ${ }^{19}$ (100 mM, pH 7.5; see the rationale for alteration in the Methods section); the rate of NADH formation remained constant regardless of the electrolyte type (Supplementary Fig. 7). Controlled potential electrolysis at -0.2 $\mathrm{V}_{\mathrm{RHE}}$ resulted in enzymatic conversion of 2-methyl-2-cyclohexen-1-one to $(R)$-2-methylcyclohexanone $(e e>99 \%)$ with a rate of $1.16 \pm 0.16 \mathrm{mM} \mathrm{h}^{-1}$ and a $\mathrm{TOF}_{T S} \mathrm{OYE}$ of 230 $\pm 30 \mathrm{~h}^{-1}$ (Fig. $\left.2 \mathbf{h}\right)$. The rate of enzymatic reaction was similar than that of NADH regeneration reaction (Supplementary Fig. 7). The bioelectrocatalytic reaction required $\mathbf{M}_{\mathbf{o x}}, \mathrm{NAD}^{+}, T s \mathrm{OYE}$, and electrical bias (Fig. 2h).

\subsection{Photoanodic electron extraction from microplastics}


To provide electrons for the CFP-based cathodes, we chose $\alpha-\mathrm{Fe}_{2} \mathrm{O}_{3}$ because of its (i) earthabundance ( $\mathrm{Fe}$ and $\mathrm{O}$ as the fourth and first most abundant elements in the Earth's crust, respectively), ${ }^{21}$ (ii) non-toxicity, ${ }^{21}$ and (iii) excellent PEC stability under alkaline conditions (pH 13.6) ${ }^{21}$, compared with visible-light-absorbing metal oxide semiconductors [e.g., $\mathrm{BiVO}_{4}$ (unstable at $\mathrm{pH}>11)^{22}, \mathrm{WO}_{3}$ (unstable at $\left.\left.\mathrm{pH}>4\right)^{23}\right]$. We synthesized a $\alpha-\mathrm{Fe}_{2} \mathrm{O}_{3}$ photoelectrode by (i) hydrothermally depositing akaganeite $(\beta-\mathrm{FeOOH})$ on a fluorine-doped tin oxide substrate and (ii) thermally converting $\beta$-FeOOH into worm-like $\alpha-\mathrm{Fe}_{2} \mathrm{O}_{3}(90 \pm 12 \mathrm{~nm}$ in diameter, $312 \pm 91 \mathrm{~nm}$ in length; Figs. 3a and 3b). Characterization details using analytical tools (e.g., SEM, XPS, X-ray diffraction) are shown in Figs. 3a and 3b and Supplementary Fig. 8 and their legends. We investigated its optical and electronic properties because these photophysical properties determine PEC efficiencies. According to our ultraviolet-visible spectroscopy, the $\alpha-\mathrm{Fe}_{2} \mathrm{O}_{3}$ absorbed ultraviolet and visible light below approximately $580 \mathrm{~nm}$ with a bandgap of $2.00 \mathrm{eV}$ (Supplementary Figs. 8f and 8g). From $\alpha-\mathrm{Fe}_{2} \mathrm{O}_{3}$ 's ultraviolet photoelectron spectrum, we estimated its valence band edge potential, and conduction band edge potential to be 2.52 and 0.52

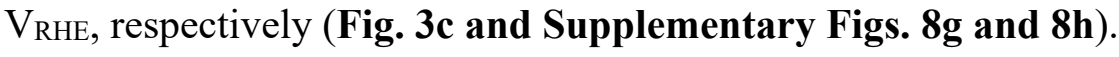

We investigated $\alpha-\mathrm{Fe}_{2} \mathrm{O}_{3}$ 's PEC performance on electron extraction from PET microplastics for different conditions at $303 \mathrm{~K}$ : (i) no bias under dark, (ii) anodic bias (1.0 $\left.\mathrm{V}_{\mathrm{RHE}}\right)$ under dark, (iii) no bias under solar light [air mass 1.5 global (AM 1.5G); $100 \mathrm{~mW} \mathrm{~cm}^{-2}$ ], and (iv) the anodic bias under solar light. Note that the photoelectrocatalytic experiments began immediately as soon as we prepared an unpretreated PET solution by adding PET microplastics (size $\leq c a .5 \mathrm{~mm}$ ) in aqueous 5 $\mathrm{M} \mathrm{NaOH}$ electrolyte solution (1 $\mathrm{mg} \mathrm{mL}^{-1}$; see Methods section for details). Quantitative ${ }^{1} \mathrm{H}$ NMR spectroscopy of the PET showed the solubilization of PET to ethylene glycol (EG) and benzene-1,4dicarboxylate (BD) in conditions (i), (ii), and (iii) (Supplementary Fig. 9), which we attribute to 
the alkaline hydrolysis of PET's ester functional groups. In stark contrast, the positive groupcondition (iv) - resulted in the formation of $530 \pm 23 \mathrm{nmol}$ formate and $185 \pm 9 \mathrm{nmol}$ acetate (Supplementary Fig. 9a). These results signify that $\alpha-\mathrm{Fe}_{2} \mathrm{O}_{3}$ photoanode extracts electrons and produces organic fuels from solubilized nonrecyclable microplastics.

\subsection{Mechanistic investigation}

We performed mechanistic analyses to examine the underlying photoredox chemistry driven by $\alpha$ $\mathrm{Fe}_{2} \mathrm{O}_{3}$. For the analyses, we constructed a two-compartment, three-electrode configuration using a salt bridge, which maintains electrical neutrality within the internal circuit. We confirmed that PET reformation occurs through the photooxidative pathway; as shown in Supplementary Fig. 10a, we detected formate and acetate in the anodic site, not the cathodic site. Because the photoanode generated photoexcited holes, $\mathrm{O}_{2}, \mathrm{H}_{2} \mathrm{O}_{2}$, and $\mathrm{OH}^{*}$ (Supplementary Fig. 10b), we investigated which species drove the waste-to-chemical conversion. As shown in Fig. 3c, the addition of $\mathrm{Na}_{2} \mathrm{SO}_{3}$ (hole scavenger) suppressed the reaction, whereas (i) the presence of sodium pyruvate $\left(\mathrm{H}_{2} \mathrm{O}_{2}\right.$ scavenger) or tert-butyl alcohol $\left(\mathrm{OH}^{*}\right.$ radical scavenger) and (ii) the purging with $\mathrm{N}_{2}$ gas did not restrain the formation of formate and acetate. Note that $\mathrm{H}_{2} \mathrm{O}_{2}$ and $\mathrm{O}_{2}$ themselves do not execute the target reaction under dark conditions without electrical bias (Supplementary Fig. 10c). These results indicate that photoexcited hole is solely responsible for the photooxidative reaction.

Because the alkaline solubilization of PET microplastics resulted in a formation of EG and BD (Supplementary Fig. 9b), we investigated which molecules reacted with $\alpha-\mathrm{Fe}_{2} \mathrm{O}_{3}$ 's photoexcited holes. Our ${ }^{1} \mathrm{H}$ and ${ }^{13} \mathrm{C}$ NMR spectroscopic analyses show that photoelectroactivated $\alpha-\mathrm{Fe}_{2} \mathrm{O}_{3}$ oxidizes EG to a variety of products (Supplementary Figs. 11a and 11b). The oxidation products included $\mathrm{C} 2$ intermediates (e.g., glyoxal, glycolate, glyoxylate) and $\mathrm{C} 1$ products (e.g., 
formate, acetate). The oxidation intermediates were reported ${ }^{24,25}$ to be (i) formed through the oxidation reaction of EG, and (ii) further oxidized to formate and acetate under alkaline conditions. The photoactivated $\alpha-\mathrm{Fe}_{2} \mathrm{O}_{3}$ oxidized the $\mathrm{C} 2$ intermediates to formate and acetate (Supplementary Figs. 11c, 11d, and 11e). On the other hand, $\alpha-\mathrm{Fe}_{2} \mathrm{O}_{3}$ did not oxidize $\mathrm{BD}$ during the PEC reaction (Supplementary Fig. 11f), which we attribute to the difficulty of oxidizing stable aromatic moieties.

We observed the dependency of PEC oxidation rates on applied bias and PET concentration. In the kinetic experiments, we prepared a pretreated PET solution $\left(5 \mathrm{mg} \mathrm{mL}^{-1}\right.$; see the Methods section for the details) to use it as an electrolyte solution; this pretreatment step solubilizes the solid wastes in advance, which facilitates contact between the photoelectrocatalyst and the substrates. Our linear sweep voltammetric analysis shows that anodic currents of $\alpha-\mathrm{Fe}_{2} \mathrm{O}_{3}$ increase with increasing applied bias and PET concentration under light conditions, not dark conditions (Supplementary Figs. 12a and 12b). Consistent with the result, the production rate of formate and acetate increased with increasing applied bias from 0.7 to $1.2 \mathrm{~V}$ RHE and PET concentration from 0 to $10 \mathrm{mg} \mathrm{mL}^{-1}$ (Supplementary Figs. 12c and 12d).

\subsection{Hematite doping for enhanced photoanodic reactions}

The separation of photoexcited charge carriers plays a decisive role in the efficiency of photoelectrocatalytic reactions because it increases the concentration of charge carriers that participate in a photoredox reaction. We hypothesized that doping treatment of $\alpha-\mathrm{Fe}_{2} \mathrm{O}_{3}$ can boost the efficiency of the waste-to-chemical reaction because the strategy (i) increases electron concentration to enhance electrical conductivity and suppress charge recombination, and (ii) makes $\alpha-\mathrm{Fe}_{2} \mathrm{O}_{3}$ 's band bending more upward to provide a strong driving force for charge separation. ${ }^{26,27}$ Thus, we introduced $\mathrm{Zr}^{4+}$ atoms into the $\alpha-\mathrm{Fe}_{2} \mathrm{O}_{3}$ nanostructure to synthesize a $\mathrm{Zr}$-doped $\alpha-\mathrm{Fe}_{2} \mathrm{O}_{3}$ 
$\left(\mathrm{Zr}: \alpha-\mathrm{Fe}_{2} \mathrm{O}_{3}\right)$ photoanode because the dopant ${ }^{28}$ is reported to (i) provide electrons for $\alpha-\mathrm{Fe}_{2} \mathrm{O}_{3}$ and (ii) accelerate electron transport between Fe atoms, in terms of small polaron model as conduction mechanism, which are beneficial for increasing carrier conductivity. The $\mathrm{Zr}$ doping insignificantly altered the phase, morphology, optical bandgap, and band edge potentials of the photoanode (Supplementary Fig. 13 and its legend).

We observed the enhanced PEC performance of the $\mathrm{Zr}: \alpha-\mathrm{Fe}_{2} \mathrm{O}_{3}$; the photoanodic current of $\mathrm{Zr}: \alpha-\mathrm{Fe}_{2} \mathrm{O}_{3}$ increased considerably and the onset potential of water oxidation was cathodically shifted by $0.18 \mathrm{~V}$ when we used $2 \mathrm{mM} \mathrm{Zr}^{4+}$ ions in the precursor solution (Supplementary Fig. 14). We attribute the improved performance to (i) increased electron concentration (Supplementary Fig. 15a), (ii) enhanced charge separation dynamics (Supplementary Fig. 15b), (iii) decreased chargetransfer resistances at $\mathrm{Zr}: \alpha-\mathrm{Fe}_{2} \mathrm{O}_{3}$ interface (Supplementary Figs. 15c and 15d), (iv) suppressed charge recombination (Supplementary Fig. 16), and (v) more upward band bending (Supplementary Fig. 15a), which we obtained using (transient) voltammetric analysis, MottSchottky analysis, and electrochemical impedance spectroscopy. Detailed analytical results are shown in Supplementary Information (Supplementary Figs. 15 and 16 and their legends).

These photophysical improvements caused by $\mathrm{Zr}$ doping resulted in a faster PET reformation. Fig. 3d displays that the $\mathrm{Zr}: \alpha-\mathrm{Fe}_{2} \mathrm{O}_{3}$ exhibits a faster production of formate and acetate than does the $\alpha-\mathrm{Fe}_{2} \mathrm{O}_{3}$ photoanode from 0.8 to $1.2 \mathrm{~V}$ RHE. Consistent with the results, the $\mathrm{Zr}: \alpha-\mathrm{Fe}_{2} \mathrm{O}_{3}$ photoanode generated a higher photoanodic current than $\alpha-\mathrm{Fe}_{2} \mathrm{O}_{3}$ did under the same PET concentrations (Fig. 3e), which is beneficial to faster electron transport to CFP-based cathodes for rapid biocatalytic reactions.

We confirmed $\mathrm{Zr}: \alpha-\mathrm{Fe}_{2} \mathrm{O}_{3}$ 's robust photoelectrocatalytic stability. As shown in Supplementary Fig. 17a, $\mathrm{Zr}: \alpha-\mathrm{Fe}_{2} \mathrm{O}_{3}$ exhibited a steady formation rate of formate and acetate 
during a four-iteration experiment (12-h reaction per cycle). In addition, $\mathrm{Zr}: \alpha-\mathrm{Fe}_{2} \mathrm{O}_{3}$ 's phase and surface chemical states did not alter and its constituent atoms did not leak into an electrolyte solution after the reusability test (Supplementary Figs. 17b and 17c and Supplementary Tables 2 and 3). These results indicate its propriety in long-term photoelectrocatalytic reactions.

Furthermore, we revealed the real-world applicability of the $\mathrm{Zr}: \alpha-\mathrm{Fe}_{2} \mathrm{O}_{3}$ energy material using microplastics from post-consumer PET wastes including a PET disposable cup from Starbucks coffee company and a PET bottle from Coca-Cola company (Supplementary Figs. 18a and 18b). The application of solar energy (1 sun) and electrical bias (1.1 V $\mathrm{RHE})$ to the photoanode triggered the formation of approximately $1.7 \mathrm{mmol}$ formate and $40 \mu \mathrm{mol}$ acetate from an unprehydrolyzed Starbucks PET cup and a Coca-Cola PET bottle for 10 days (Supplementary Figs. 18c-18f).

\subsection{Photobiocatalytic synthesis fueled by real-world microplastics}

Having substantiated CFP-mediated biosynthetic reactions and $\mathrm{Zr}: \alpha-\mathrm{Fe}_{2} \mathrm{O}_{3}$-driven transformation reactions, we integrated these two redox reactions in a two-compartment, two-electrode configuration (working electrode: $\mathrm{Zr}: \alpha-\mathrm{Fe}_{2} \mathrm{O}_{3}$ photoanode, counter electrode: AQC/CFP or CFP cathode). We prepared a pretreated PET solution — using microplastics from Starbucks PET cupas an anodic electrolyte solution. The controlled potential photoelectrolysis triggered biocatalytic synthesis, including (i) rAaeUPO-driven production of enantiopure (R)-1-phenylethanol (Fig. 4a),

(ii) GDH-driven formation of L-glutamate (Fig. 4b), and (iii) TsOYE-catalyzed generation of enantiopure (R)-2-methylcyclohexanone (Fig. 4c). The enantioselectivities remained constant (ee > 99\%) regardless of the scale of applied bias (Figs. 4a and 4c). Sheltering the PEC system from solar light made the synthetic reactions sluggish or imperceptible (Fig. 4), signifying that solar energy is a key energy resource to drive the redox reactions in a meaningful rate. We also revealed that rates 
of photobiosynthetic reactions increased with PET concentration from 0 to $50 \mathrm{mg} \mathrm{mL}-1$ (Supplementary Fig. 19), which indicates that PET provides electron donors (e.g., EG) for boosting enzymatic transformation reactions.

Using optimized applied bias of each enzymatic reaction, our photobiocatalytic system exhibited a TTN $\mathrm{T}_{\mathrm{r} A a e \mathrm{UPO}}$ of 113,000 (3 h), a TTN $\mathrm{TDH}_{\mathrm{GH}}$ of 144,000 (56 h), and a TTN $_{T s} \mathrm{OYE}$ of 1,300 (7 h) (Fig. 5 and Supplementary Fig. 20a). The reaction times of GDH and $T s O Y E$ were longer than those reported in precedent research on biocatalytic PEC systems ${ }^{13,29-31}$, which we attribute to the robustness of the $\mathrm{Zr}: \alpha-\mathrm{Fe}_{2} \mathrm{O}_{3} \mid \mathrm{CFP}$ system and the biocatalysts. However, the raaeUPO reaction halted at ca. $2 \mathrm{~h}$ (Supplementary Fig. 20a), which was shorter than that recorded in a previous biocatalytic PEC study ${ }^{32}$. We found that the CFP cathode formed $\mathrm{OH}^{\bullet}$ radicals (Supplementary Fig. 20b), which are reported ${ }^{32,33}$ to readily deactivate the enzyme. Because electrochemical reduction of $\mathrm{H}_{2} \mathrm{O}_{2}$ forms $\mathrm{OH}^{\bullet}$ radicals $\left[\mathrm{H}_{2} \mathrm{O}_{2}+\mathrm{e}^{-} \rightarrow \mathrm{OH}^{\bullet}+\mathrm{OH}^{-}, E_{\text {red }}=0.79 \mathrm{~V}_{\mathrm{RHE}}\right]^{32}$, we decreased the applied bias from 1.2 to $0.9 \mathrm{~V}$, which resulted in a negligible formation of the radical (Supplementary Fig. 20b). This strategy resulted in a steady biosynthetic reaction with a $\mathrm{TTN}_{\mathrm{r} A a e \mathrm{UPO}}$ of $271,000(7 \mathrm{~h})$ (Fig. 5 and Supplementary Fig. 20a). $\mathrm{Zr}: \alpha-\mathrm{Fe}_{2} \mathrm{O}_{3}$ produced formate and acetate during the photoelectrocatalytic reactions (Supplementary Table 4), which indicates the production of valueadded compounds simultaneously at the anodic and cathodic sites.

We demonstrated a broad applicability of the photobiosynthetic platform by extending the substrate scope (Supplementary Table 5). Fig. 5 displays (i) rAaeUPO-mediated synthesis of (R)1,2,3,4-tetrahydro-1-naphthol (ee > 99\%, TOF: 48,000 h${ }^{-1}$, TTN: 312,000), cyclohexanol (TOF: 36,000 $\mathrm{h}^{-1}$, TTN: 234,000$)$, and $(1 R, 2 S)-1$-phenylpropylene oxide $\left(e e>99 \%\right.$, TOF: $64,000 \mathrm{~h}^{-1}$, TTN: 362,000) and (ii) TsOYE-driven production of cyclohexanone (TOF: $420 \mathrm{~h}^{-1}$, TTN: 1,300) and 3phenylpropionaldehyde (TOF: $140 \mathrm{~h}^{-1}$, TTN: 690). The biocatalytic PEC platform compares 
favorably with the state-of-the-art biocatalytic PEC systems in a two-electrode configuration (Fig. 6). The reported PEC cells $\mathrm{s}^{13,30-32}$ extracted electrons from water to trigger redox biotransformations driven by rAaeUPO $\left(\mathrm{TTN}_{\mathrm{r} A a e \mathrm{UPO}}<50,000\right)^{31,32}$, GDH $\left(\mathrm{TTN}_{\mathrm{GDH}}: 108,000\right)^{13}$, or $T_{s} \mathrm{OYE}\left(\mathrm{TTN}_{T s} \mathrm{OYE}\right.$ $<256)^{30,31}$. Our photoelectrocatalytic system acquired electrons from hydrolyzed PET solutions and accelerated enzymatic synthetic reactions with the highest $\mathrm{TTN}_{\text {enzyme }}\left(\mathrm{TTN}_{\mathrm{r} A a e \mathrm{UPO}}: 362,000, \mathrm{TTN}_{\mathrm{GDH}}\right.$ :

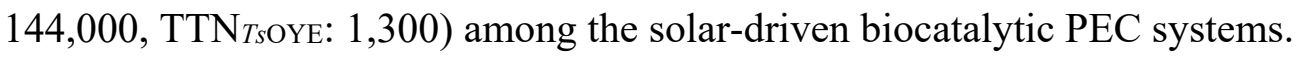

\section{Discussion}

Inspired by natural photosynthesis, biocatalytic PEC platforms synthesize value-added compounds through the synergistic coupling of photoelectrocatalysis and redox biotransformations ${ }^{12,34}$. Mechanistically, a photoelectrode absorbs solar light and transfers its photoexcited charge carriers to the catalytic center of redox enzymes, which subsequently catalyze synthetically useful redox reactions (e.g., asymmetric hydrogenation of $\mathrm{C}=\mathrm{C}$ bonds, amination of $\mathrm{C}=\mathrm{O}$ bonds, hydroxylation of $\mathrm{C}-\mathrm{H}$ bonds, epoxidation of $\mathrm{C}-\mathrm{H}$ bonds $)^{12}$. Biocatalytic PEC system has emerged as an alternative platform to biocatalytic photochemical system due to its merits ${ }^{12,31,34}$, such as (i) suppression of undesirable back electron transfer and electron-hole recombination, (ii) independent examination of cathodic and anodic reactions, (iii) design of individual redox (photo)electrocatalysts, (iv) physical separation of anodic and cathodic sites, and (v) facile reusability of catalytic electrodes.

The majority of biocatalytic PEC systems ${ }^{13,30,32,35,36}$ have focused water oxidation to provide the reducing equivalents needed to drive reductive enzymatic reactions. However, water oxidation poses significant limitations, such as its sluggish reaction rate caused by anodic four-electron (or two-electron) process ${ }^{19}$ and the relatively low value of dioxygen ${ }^{37}$. This issue made us hypothesize 
that finding another electron feedstock would accelerate enzymatic synthetic reactions and produce value-added chemicals simultaneously on oxidation and reduction sites.

The current work first demonstrates that real-world microplastics can provide electron feedstocks to expedite photobiosynthetic reactions with excellent TTNs. The two-compartment biocatalytic PEC system provides distinct advantages that are impossible in photocatalytic processes using homogeneous or heterogeneous photocatalysts: (i) flexible combination of redox reactions (e.g., EG oxidation with $\mathrm{H}_{2} \mathrm{O}_{2}$ production and $\mathrm{NADH}$ regeneration) with different reaction conditions [e.g., $\mathrm{KPi}$ buffer $(\mathrm{pH}$ 6.0) with $\mathrm{NaOH}$ alkaline solution], (ii) spatial separation of enzymatic products [e.g., $(R)$-1-phenylethanol, L-glutamate, $(R)$-2-methylcyclohexanone] and oxidation products (e.g., formate, acetate), (iii) protection of reduced electron mediators (e.g., $\mathbf{M}_{\text {red, }}$ $\mathrm{NADH}$ ) and enzymes from photooxidation, (iv) control of applied bias to drive redox reactions selectively (e.g., $\mathrm{H}_{2} \mathrm{O}_{2}$ production without $\mathrm{OH}^{*}$ generation), and (v) development of individual (photo)electrodes (e.g., $\mathrm{Zr}: \alpha-\mathrm{Fe}_{2} \mathrm{O}_{3}, \mathrm{AQC} / \mathrm{CFP}$ ). Follow-up studies are needed to ameliorate the photoanodic performance of electron extraction through, for example, (i) modification of surface morphology to decrease charge recombination and (ii) construction of junctions to improve charge separation. In addition, functionalization of cathodes with additional catalysts would accelerate enzymatic reactions by boosting interfacial charge transfer to enzyme activators. These attempts will further expand the scope of our approach to other redox enzymatic reactions (e.g., hydrogenasedriven evolution of $\mathrm{H}_{2}$, Baeyer-Villiger monooxygenase-mediated formation of esters and lactones) with improved efficiencies.

\section{Conclusions}


This study reports solar-assisted e-biorefinery approach that uses PET microplastics as an electron feedstock for redox biosynthesis. The $\mathrm{Zr}: \alpha-\mathrm{Fe}_{2} \mathrm{O}_{3} \mid \mathrm{AQC} / \mathrm{CFP}$ and $\mathrm{Zr}: \alpha-\mathrm{Fe}_{2} \mathrm{O}_{3} \mid \mathrm{CFP}$ hybrids produced value-added chemicals at the anodic and cathodic sites through simultaneous enzymatic synthetic reactions (e.g., rAaeUPO-driven hydroxylation/epoxidation, GDH-mediated amination, and $T s \mathrm{OYE}-$ catalyzed hydrogenation) and EG oxidation. The photoanodic half-reaction by $\alpha-\mathrm{Fe}_{2} \mathrm{O}_{3}$ led to (ii) extracted electrons to the CFP-based cathodes, and (i) yielded valuable chemicals (e.g., formate and acetate). To accelerate the photoanodic extraction of electrons, we synthesized the Zr: $\alpha$ $\mathrm{Fe}_{2} \mathrm{O}_{3}$ photoanode that exhibited improved charge separation efficiencies $\left(\Delta \eta_{\text {bulk }}\right.$ of 3.5 to $10 \%$, $\Delta \eta_{\text {surface }}$ of 15 to $60 \%$ ), decreased charge-transfer resistance (by up to 17 times), cathodic shift of flat-band potential by $0.16 \mathrm{~V}$, and reduced charge recombination behaviors. Furthermore, the Zr: $\alpha$ $\mathrm{Fe}_{2} \mathrm{O}_{3}$ photoanode reformed real-world PET samples, including PET microplastics from Starbucks and Coca-Cola's commercial PET items for over 10 days. The microplastic-fueled PEC biocatalysis showed a broad applicability to various enzymatic substrates and achieved benchmark performances (TTN $\left.\mathrm{r}_{\mathrm{r} a a e \mathrm{UPO}}: 362,000, \mathrm{TTN}_{\mathrm{GDH}}: 144,000, \mathrm{TTN}_{T s} \mathrm{OYE}: 1,300\right)$.

\section{Methods}

Characterization of carbon fiber paper. We bought a commercial carbon fiber paper (CFP) from HanTech (Korea). Before performing any experiments, we washed CFP using deionized water, ethanol, and acetone, and dried it under vacuum at room temperature. We used an ultra-high resolution scanning electron microscope SU8230 (Hitachi High-Tech Corp., Japan) to observe the morphology of the CFP. We employed a K-Alpha X-ray photoelectron spectrometer (ThermoFisher Scientific Inc., USA) to investigate chemical states of the CFP. We obtained a CFP's Raman 
spectrum using used a LabRAM HR Evolution Raman microscope (Horiba, Ltd., Kyoto, Japan) with an excitation wavelength of $514 \mathrm{~nm}$.

Preparation of anthraquinone-2-carboxylic acid-anchored carbon fiber paper. We purified a commercial CFP as mentioned above. To prepare anthraquinone-2-carboxylic acid-anchored carbon fiber paper (AQC/CFP), we immersed the CFP in an ethanolic solution containing $3 \mathrm{mM}$ AQC for $24 \mathrm{~h}$. Subsequently, we dried it at room temperature in air. We estimated the amount of surfacebound AQC using cyclic voltammetric analysis; the surface concentration of AQC ( $\left.\Gamma_{\mathrm{AQC}}\right)$ was estimated using Equation 1

$$
\Gamma_{\mathrm{AQC}}\left(\mathrm{nmol} \mathrm{cm}{ }^{-2}\right)=Q \times(n \times F \times A)^{-1}
$$

where $Q$ is the charge consumed for AQC's reduction, which was calculated from a cyclic voltammogram of the AQC-anchored CFP, $n$ is the number of electrons transferred to AQC $(n=2)$, F is the Faraday constant $\left(96,485 \mathrm{C} \mathrm{mol}^{-1}\right)$, and $A$ is the geometrical surface area of the CFP. We obtained Nyquist plots of CFP and AQC/CFP electrodes using an impedance analyzer (ZIVE SP1, WonATech Co., Korea) at an AC potential amplitude of $10 \mathrm{mV}$. We fitted the Nyquist plots to calculate their charge-transfer resistances using a Zman software (WonATech Co., Korea).

Electrocatalytic production of $\mathbf{H}_{2} \mathrm{O}_{2}$. Electrocatalytic production of $\mathrm{H}_{2} \mathrm{O}_{2}$ was performed in a three-electrode configuration, which consisted of a working electrode, an $\mathrm{Ag} / \mathrm{AgCl}(3 \mathrm{M} \mathrm{NaCl})$ reference electrode, and a graphite rod counter electrode in a same compartment. An electrolyte solution was a potassium phosphate buffer $(100 \mathrm{mM}, \mathrm{pH} 6.0,2 \mathrm{~mL})$. When we applied an electrical bias to this system, we used a potentiostat/galvanostat (WMPG 1000, WonATech Co., Korea). 
When we investigate the pathway of the electrochemical production of $\mathrm{H}_{2} \mathrm{O}_{2}$, we supplemented 10 $\mathrm{mM}$ 1,4-benzoquinone $\left(\mathrm{O}_{2}{ }^{-{ }^{-}}\right.$scavenger $)$into the electrolyte solution. All potentials have been quoted vs. reversible hydrogen electrode (RHE) according to Equation 2

$$
E_{\mathrm{RHE}}(\mathrm{V})=E_{\mathrm{Ag} / \mathrm{AgCl}}(\mathrm{V})+0.209+(0.059 \times \mathrm{pH})
$$

After the electrochemical reaction, we collected a reaction solution, and mixed it with a colorimetric reagent solution [3.0 U HRP and $2 \mathrm{mM}$ ABTS in a phosphate solution (100 mM, pH 5.0)]. We monitored its absorbance at $420 \mathrm{~nm}$ using a V-650 UV-Vis absorption spectrophotometer (JASCO Inc., Japan).

Electrobiocatalytic oxyfunctionalization reactions. We applied AQC/CFP-driven $\mathrm{H}_{2} \mathrm{O}_{2}$ production to $\mathrm{r} A a e \mathrm{UPO}$-mediated oxyfunctionalization reactions in a one-compartment, threeelectrode configuration [working electrode: $\mathrm{AQC} / \mathrm{CFP}$, reference electrode: $\mathrm{Ag} / \mathrm{AgCl}(3 \mathrm{M} \mathrm{NaCl})$, counter electrode: $\mathrm{CFP}$ ]. In the three-electrode configuration, an electrolyte solution was an $\mathrm{O}_{2}$-rich KPi buffer (100 mM, pH 6.0,2 mL) containing $50 \mathrm{nM} \mathrm{rAaeUPO}$ and $16 \mathrm{mM}$ ethylbenzene. After the biocatalytic electrochemical reaction, we extracted oxyfunctionalized products using ethyl acetate, dried them over $\mathrm{MgSO}_{4}$, and quantified them using a 7890A gas chromatograph (Agilent Technologies, USA) equipped with a flame ionization detector and a CP-Chirasil-Dex CB column $(25 \mathrm{~m} \times 0.32 \mathrm{~mm} \times 0.25 \mu \mathrm{m})$.

Electrocatalytic regeneration of NADH. When we investigated the capability of CFP to reduce $\mathrm{NAD}^{+}$to $\mathrm{NADH}$, we immersed a CFP electrode in a sodium phosphate buffer $(100 \mathrm{mM}, \mathrm{pH} 7.5,2$ $\mathrm{mL}$ ) containing $\mathrm{NAD}^{+}$and $\mathbf{M}_{\mathbf{0} \mathbf{x}}$ in three-electrode configuration. A reference electrode and counter 
electrode were $\mathrm{Ag} / \mathrm{AgCl}(3 \mathrm{M} \mathrm{NaCl})$ and a graphite rod, respectively. We used a potentiostat/galvanostat (WMPG 1000, WonATech Co., Korea) to perform electrocatalytic analysis and controlled potential electrolysis. When we obtained linear sweep voltammograms and performed NADH regeneration tests, we added $0.25 \mathrm{mM} \mathrm{M}_{\mathbf{x x}}$ and $1 \mathrm{mM} \mathrm{NAD}^{+}$in an $\mathrm{O}_{2}$-depleted NaPi buffer. We quantified NADH using a V-650 UV-Vis absorption spectrophotometer (Jasco Inc., Japan). Nuclear magnetic resonance spectroscopic (NMR) analysis was performed to prove the formation of 1,4-NADH. We used a $400 \mathrm{MHz}$ AVANCE III HD Nanobay (Bruker Corp., USA) equipped with a tunable multinuclear probe (PA BBO 400S1 BBF-H-D-05 Z plus).

Electrobiocatalytic amination and hydrogenation. When we performed enzymatic amination reactions, we added $500 \mathrm{nM} \mathrm{GDH}, 80 \mathrm{mM} \alpha$-ketoglutarate, $250 \mathrm{mM} \mathrm{NH}_{4}^{+}, 0.25 \mathrm{mM} \mathbf{M}_{\mathbf{o x}}$, and 1 $\mathrm{mM} \mathrm{NAD}{ }^{+}$in an $\mathrm{O}_{2}$-depleted $\mathrm{NaPi}$ buffer $(100 \mathrm{mM}, \mathrm{pH} 7.5,2 \mathrm{~mL})$. A controlled potential electrolysis was performed in a three-electrode configuration [working electrode: CFP, reference electrode: $\mathrm{Ag} / \mathrm{AgCl}(3 \mathrm{M} \mathrm{NaCl})$, counter electrode: graphite rod]. The concentrations of $\alpha$ ketoglutarate and L-glutamate were measured using a high-performance liquid chromatography (1260 Infinity liquid chromatography system, Agilent Technologies, USA) equipped with a variable wavelength detector and an Intersil C18 column. The eluent was a phosphoric acid aqueous solution

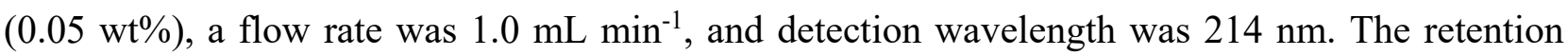
times of $\alpha$-ketoglutarate and L-glutamate were 9.5 and $3.1 \mathrm{~min}$, respectively. When we drove enzymatic hydrogenation reactions, we added $5 \mu \mathrm{M}$ Ts OYE, 7 mM 2-methyl-2-cyclohexen-1-one, $10 \mathrm{mM} \mathrm{CaCl}_{2}, 20 \mathrm{mM} \mathrm{NH}_{4}{ }^{+}, 0.25 \mathrm{mM} \mathrm{M}_{\mathbf{0 x}}$, and $1 \mathrm{mM} \mathrm{NAD}^{+}$in an $\mathrm{O}_{2}$-depleted triethanolamine (TEOA)-buffered solution (100 mM, pH 7.5, $2 \mathrm{~mL})$. This experiment was also performed in a threeelectrode configuration [working electrode: $\mathrm{CFP}$, reference electrode: $\mathrm{Ag} / \mathrm{AgCl}(3 \mathrm{M} \mathrm{NaCl})$, counter 
electrode: graphite rod]. The products of $T_{s} \mathrm{OYE}$ were quantified using a 7890A gas chromatograph (Agilent Technologies, USA) equipped with a flame ionization detector and a CP-Chirasil-Dex CB column $(25 \mathrm{~m} \times 0.32 \mathrm{~mm} \times 0.25 \mu \mathrm{m})$.

Fabrication of photoanodes. We synthesized a hematite photoanode via solution-based processing and high temperature annealing. A commercial fluorine-doped tin oxide glass (TEC-7, Pilkington) was rinsed with acetone, isopropyl alcohol, and deionized water. To deposit a $\beta$-FeOOH nanostructure on the $\mathrm{F}: \mathrm{SnO}_{2}$ substrate, we prepared a precursor solution containing 150 $\mathrm{mM} \mathrm{FeCl} \cdot 6 \mathrm{H}_{2} \mathrm{O}$ and $1 \mathrm{M} \mathrm{NaNO}_{3}$ in deionized water. The substrate was immersed in the solution and heated in a Lindberg/Blue M muffle furnace (Fisher Scientific Co., USA) at $100{ }^{\circ} \mathrm{C}$ for $6 \mathrm{~h}$. To transform $\beta$-FeOOH into $\alpha-\mathrm{Fe}_{2} \mathrm{O}_{3}$, the electrode was annealed at $800{ }^{\circ} \mathrm{C}$ for $20 \mathrm{~min}$. When we prepared a $\mathrm{Zr}: \alpha-\mathrm{Fe}_{2} \mathrm{O}_{3}$, we supplemented $\mathrm{ZrCl}_{4}(0$ to $2.5 \mathrm{mM})$ into the precursor solution, and followed the aforementioned method.

Preparation of PET-containing electrolyte solutions. Granular PET polymers (Sigma-Aldrich) or a commercial PET item (from Starbucks coffee company, or Coca-Cola company) was ground to microplastics (size $\leq c a .5 \mathrm{~mm}$ ) using a commercial coffee grinder. After we prepared an electrolyte solution by adding the microplastics in $5 \mathrm{M} \mathrm{NaOH}$ solution, we immediately conducted (photo)electrocatalytic reactions unless otherwise specified. We designated the solution "unpretreated PET solution", and its concentration was mentioned in a main text, figure, or figure legend. When we prepared a "pretreated PET solution", we immersed the microplastics in $5 \mathrm{M}$ $\mathrm{NaOH}$ solution for 3 days at $353 \mathrm{~K}$ under dark conditions with stirring at $700 \mathrm{rpm}$ unless otherwise specified; the amounts of the microplastics were mentioned in a main text, figure, or figure legend. 
The concentration of ethylene glycol after pretreatment was approximately $200 \mathrm{mM}$ as determined by quantitative nuclear magnetic resonance spectroscopy.

Photoelectrochemical reformation of PET. PEC reformation of PET was performed in a threeelectrode configuration. The configuration consisted of a working electrode, an $\mathrm{Hg} / \mathrm{HgO}(1 \mathrm{M} \mathrm{NaOH})$ reference electrode, and a Pt counter electrode in a same compartment. The geometrical surface areas of photoanodes were $1.7 \mathrm{~cm}^{2}$. When we performed controlled potential photoelectrolysis to drive PEC reformation PET, (i) the electrolyte volume was $2 \mathrm{~mL}$ unless otherwise specified, (ii) the light source was a xenon lamp (Newport Co., USA) that emitted a simulated solar light (light intensity: 1 sun), and (iii) an electrical bias was provided using a potentiostat/galvanostat (WMPG 1000, WonATech Co., Korea). All potentials have been quoted vs. reversible hydrogen electrode (RHE) according to the following equation (Equation 3)

$$
E_{\mathrm{RHE}}(\mathrm{V})=E_{\mathrm{Hg} / \mathrm{HgO}}(\mathrm{V})+0.140+(0.059 \times \mathrm{pH})
$$

When we investigated which species (e.g., $\mathrm{h}^{+}, \mathrm{H}_{2} \mathrm{O}_{2}, \mathrm{OH}^{*}$ ) performed the waste-to-chemical conversion, we used a salt bridge to separate photoanodic and cathodic site, and added $\mathrm{Na}_{2} \mathrm{SO}_{3}$ (hole scavanger), sodium pyruvate $\left(\mathrm{H}_{2} \mathrm{O}_{2}\right.$ scavanger $)$, or tert-butyl alcohol $\left(\mathrm{OH}^{*}\right.$ scavanger $)$ into an unpretreated PET solution ( $1 \mathrm{mg} \mathrm{mL}^{-1}$ PET microplastics, $\left.5 \mathrm{M} \mathrm{NaOH}\right)$. When we tested the effect of $\mathrm{O}_{2}$ on the PET reformation reaction, we purged $\mathrm{N}_{2}$ gas into the anodic electrolyte solution before and during hematite-driven photoelectrochemical (PEC) reaction.

(Quantitative) nuclear magnetic resonance spectroscopy. A ${ }^{1} \mathrm{H}$ NMR spectrum was recorded using a $400 \mathrm{MHz}$ AVANCE III HD Nanobay (Bruker Corp., USA) equipped with a tunable multinuclear probe (PA BBO 400S1 BBF-H-D-05 Z plus). We prepared a NMR sample (700 $\mu \mathrm{L})$ 
by diluting a reaction sample in a $\mathrm{D}_{2} \mathrm{O}$ solvent (v/v, 9:1) containing maleic acid (quantification standard) and DSS (chemical shift standard); $\mathrm{D}_{2} \mathrm{O}$ was used to provide an internal lock signal to correct drift in the magnetic field during the measurement. The NMR pulse sequence, relaxation delay, and temperature were zgesfpgp, $6 \mathrm{~s}$, and $298 \mathrm{~K}$. The molar concentration of analyte $\left(C_{\text {analyte }}\right)$ in the sample was calculated according to Equation 4

$$
C_{\text {analyte }}=\frac{I_{\text {analyte }} \times N_{\text {standard }}}{I_{\text {standard }} \times N_{\text {analyte }}} \times C_{\text {standard }}
$$

where $I_{\text {analyte }}$ is the integral of the analyte peak, $I_{\text {standard }}$ is the integral of the standard peak, $N_{\text {analyte }}$ is the number of protons corresponding to the analyte peak, and $N_{\text {standard }}$ is the number of protons corresponding to the standard peak.

Photoelectrochemical biocatalysis. We connected a $\mathrm{Zr}: \alpha-\mathrm{Fe}_{2} \mathrm{O}_{3}$ photoanode and a CFP cathode (or AQC/CFP cathode) in two compartment using a salt bridge. We performed controlled potential photoelectrolysis using a xenon lamp (Newport Co., USA) and a potentiostat/galvanostat (WMPG 1000, WonATech Co., Korea); solar light was designed to be irradiated to an anodic site, not a cathodic site. The geometrical surface areas of the photoanode and the cathode were 1.7 and $1 \mathrm{~cm}^{2}$, respectively, unless otherwise specified. An anodic electrolyte was a $5 \mathrm{M} \mathrm{NaOH}$ aqueous solution containing prehydrolysed PET microplastics; we prepared the microplastics by grinding Starbucks PET cup. The cathodic electrolyte was different according to the type of enzymes: (i) an $\mathrm{O}_{2}$-enriched KPi buffer (100 mM, pH 6.0) containing rAaeUPO and substrate for oxyfunctionalization reactions, (ii) an $\mathrm{O}_{2}$-depleted NaPi buffer (100 mM, pH 7.5) containing GDH, $\alpha$-ketoglutarate, $\mathrm{NH}_{4}{ }^{+}, \mathbf{M}_{\mathbf{o x}}$, and $\mathrm{NAD}^{+}$for amination reactions, and (iii) an $\mathrm{O}_{2}$-depleted TEOA buffer (100 mM, pH 7.5) containing Ts OYE, substrate, $\mathrm{Ca}^{2+}, \mathrm{NH}_{4}^{+}, \mathbf{M}_{\mathbf{x}}$, and $\mathrm{NAD}^{+}$for hydrogenation reactions. Gas chromatographic 
analysis was used to quantify enzymatic products. We calculated the total turnver numbers of rAaeUPO, GDH and TsOYE according to Equations 5, 6, and 7:

$$
\begin{aligned}
& \mathrm{TTN}_{\mathrm{r} A a e \mathrm{UPO}}=\frac{\text { Maximum product concentration during enzymatic reaction }}{\text { Concentration of } \mathrm{r} A a e \mathrm{UPO}} \\
& \mathrm{TTN}_{\mathrm{GDH}}=\frac{\text { Maximum product concentration during enzymatic reaction }}{\text { Concentration of GDH }} \\
& \mathrm{TTN}_{T S \mathrm{OYE}}=\frac{\text { Maximum product concentration during enzymatic reaction }}{\text { Concentration of } T s \mathrm{OYE}}
\end{aligned}
$$

\section{Conflicts of interest}

The authors declare no competing interests.

\section{Acknowledgements}

This work was supported by the National Research Foundation (NRF) via the Creative Research Initiative Center (grant no. NRF-2015R1A3A2066191) and the Global Ph.D. Fellowship Program (grant no. NRF-2019H1A2A1075810), Republic of Korea.

\section{Author contributions}

J.K. and C.B.P. conceptualized the work. C.B.P. supervised the research. J.K. designed and analyzed the research. J.K. performed experimental works and wrote the manuscript. C.B.P. wrote the manuscript. J.J. performed and analyzed plastic treatments. J.J. synthesized rhodium-containing electron mediators. T.H. prepared old yellow enzymes. F.H. provided unspecific peroxygenases. All authors commented on the manuscript. 


\section{Data availability}

The data supporting the findings of the study are available in the paper and its Supplementary Information.

\section{References}

1 Ryberg, M. W., Laurent, A. \& Hauschild, M. in Mapping of global plastics value chain and plastic $s$ losses to the environment (United Nations Environment Programme, 2018).

2 Adyel, T. M. Accumulation of plastic waste during COVID-19. Science 369, 1314-1315 (2020).

3 Garcia, J. M. \& Robertson, M. L. The future of plastics recycling. Science 358, 870-872 (2017).

4 MacArthur, E. Beyond plastic waste. Science 358, 843-843 (2017).

5 Ryan, P. G. in Marine Anthropogenic Litter (eds Melanie Bergmann, Lars Gutow, \& Michael Klage s) 1-25 (Springer International Publishing, 2015).

6 Law, K. L. \& Thompson, R. C. Microplastics in the seas. Science 345, 144-145 (2014).

7 Macarthur, D. E. in The New Plastics Economy: Rethinking the Future of Plastics \& Catalysing Act ion (Ellen MacArthur Foundation, 2017).

8 Singh, A. K., Yasri, N., Karan, K. \& Roberts, E. P. L. Electrocatalytic Activity of Functionalized Carbo $\mathrm{n}$ Paper Electrodes and Their Correlation to the Fermi Level Derived from Raman Spectra. ACS $A$ ppl. Energy Mater. 2, 2324-2336 (2019).

9 Molina-Espeja, P., Ma, S., Mate, D. M., Ludwig, R. \& Alcalde, M. Tandem-yeast expression system for engineering and producing unspecific peroxygenase. Enzyme Microb. Technol. 73-74, 29-33 (2015).

10 Pognon, G., Brousse, T., Demarconnay, L. \& Bélanger, D. Performance and stability of electrochem ical capacitor based on anthraquinone modified activated carbon. J. Power Sources 196, 4117-4 122 (2011).

11 Zhang, W. et al. Selective aerobic oxidation reactions using a combination of photocatalytic wat er oxidation and enzymatic oxyfunctionalizations. Nat. Catal. 1, 55-62 (2018).

12 Kim, J. \& Park, C. B. Shedding light on biocatalysis: photoelectrochemical platforms for solar-driv en biotransformation. Curr. Opin. Chem. Biol. 49, 122-129 (2019).

13 Lee, Y. W. et al. Unbiased biocatalytic solar-to-chemical conversion by $\mathrm{FeOOH} / \mathrm{BiVO}_{4} /$ perovskite $\mathrm{t}$ andem structure. Nat. Commun. 9, 4208 (2018).

14 Chaudhari, N., Landin, A. M. \& Roper, S. D. A metabotropic glutamate receptor variant functions as a taste receptor. Nat. Neurosci. 3, 113-119 (2000).

15 Sun, C. et al. I-Glutamate treatment enhances disease resistance of tomato fruit by inducing the expression of glutamate receptors and the accumulation of amino acids. Food Chem. 293, 263- 
270 (2019).

16 Hou, Y. \& Wu, G. I-Glutamate nutrition and metabolism in swine. Amino Acids 50, 1497-1510 (2 018).

17 Wang, D. et al. Lignin-fueled photoelectrochemical platform for light-driven redox biotransforma tion. Green Chem. 22, 5151-5160 (2020).

18 Son, E. J., Lee, Y. W., Ko, J. W. \& Park, C. B. Amorphous Carbon Nitride as a Robust Photocatalyst for Biocatalytic Solar-to-Chemical Conversion. ACS Sustain. Chem. Eng. 7, 2545-2552 (2019).

19 Kim, J. et al. Nicotinamide adenine dinucleotide as a photocatalyst. Sci. Adv. 5, eaax0501 (2019).

20 Mifsud, M. et al. Photobiocatalytic chemistry of oxidoreductases using water as the electron don or. Nat. Commun. 5, 3145 (2014).

21 Shen, S., Lindley, S. A., Chen, X. \& Zhang, J. Z. Hematite heterostructures for photoelectrochemic al water splitting: rational materials design and charge carrier dynamics. Energy Environ. Sci. 9, 2 744-2775 (2016).

22 Kim, J. H. \& Lee, J. S. Elaborately Modified $\mathrm{BiVO}_{4}$ Photoanodes for Solar Water Splitting. Adv. Ma ter. 31, 1806938 (2019).

23 Liu, X., Wang, F. \& Wang, Q. Nanostructure-based $\mathrm{WO}_{3}$ photoanodes for photoelectrochemical water splitting. PCCP 14, 7894-7911 (2012).

24 Uekert, T., Kasap, H. \& Reisner, E. Photoreforming of Nonrecyclable Plastic Waste over a Carbon Nitride/Nickel Phosphide Catalyst. J. Am. Chem. Soc. 141, 15201-15210 (2019).

25 Uekert, T., Kuehnel, M. F., Wakerley, D. W. \& Reisner, E. Plastic waste as a feedstock for solar-driv en $\mathrm{H} 2$ generation. Energy Environ. Sci. 11, 2853-2857 (2018).

26 landolo, B., Wickman, B., Zorić, I. \& Hellman, A. The rise of hematite: origin and strategies to red uce the high onset potential for the oxygen evolution reaction. J. Mater. Chem. A 3, 16896-1691 2 (2015).

27 Xiao, M., Luo, B., Wang, Z., Wang, S. \& Wang, L. Recent Advances of Metal-Oxide Photoanodes: Engineering of Charge Separation and Transportation toward Efficient Solar Water Splitting. Sola $r$ RRL 4, 1900509 (2020).

28 Liao, P., Toroker, M. C. \& Carter, E. A. Electron Transport in Pure and Doped Hematite. Nano Lett. 11, 1775-1781 (2011).

29 Nam, D. H. et al. Water oxidation-coupled, photoelectrochemical redox biocatalysis toward mimi cking natural photosynthesis. Appl. Catal., B 198, 311-317 (2016).

30 Son, E. J. et al. Carbon Nanotube-Graphitic Carbon Nitride Hybrid Films for Flavoenzyme-Catalyz ed Photoelectrochemical Cells. Adv. Funct. Mater. 28, 1705232 (2018).

31 Choi, D. S., Kim, J., Hollmann, F. \& Park, C. B. Solar-Assisted eBiorefinery: Photoelectrochemical P airing of Oxyfunctionalization and Hydrogenation Reactions. Angew. Chem. Int. Ed. 59, 15886-15 890 (2020).

32 Choi, D. S. et al. Bias-Free In Situ $\mathrm{H}_{2} \mathrm{O}_{2}$ Generation in a Photovoltaic-Photoelectrochemical Tande 
m Cell for Biocatalytic Oxyfunctionalization. ACS Catal. 9, 10562-10566 (2019).

33 Burek, B. O. et al. Photoenzymatic Hydroxylation of Ethylbenzene Catalyzed by Unspecific Peroxy genase: Origin of Enzyme Inactivation and the Impact of Light Intensity and Temperature. Chem CatChem 11, 3093-3100 (2019).

34 Lee, S. H., Choi, D. S., Kuk, S. K. \& Park, C. B. Photobiocatalysis: Activating Redox Enzymes by Dir ect or Indirect Transfer of Photoinduced Electrons. Angew. Chem. Int. Ed. 57, 7958-7985 (2018).

$35 \mathrm{Kim}$, J. et al. Robust $\mathrm{FeOOH} / \mathrm{BiVO}_{4} / \mathrm{Cu}(\mathrm{In}, \mathrm{Ga}) \mathrm{Se}_{2}$ tandem structure for solar-powered biocatalytic $\mathrm{CO}_{2}$ reduction. J. Mater. Chem. A 8, 8496-8502 (2020).

36 Kuk, S. K. et al. $\mathrm{CO}_{2}$-Reductive, Copper Oxide-Based Photobiocathode for Z-Scheme Semi-Artific ial Leaf Structure. ChemSusChem 13, 2940-2944 (2020).

37 Ren, Y. et al. Strategies to suppress hydrogen evolution for highly selective electrocatalytic nitro gen reduction: challenges and perspectives. Energy Environ. Sci. 14, 1176-1193 (2021). 


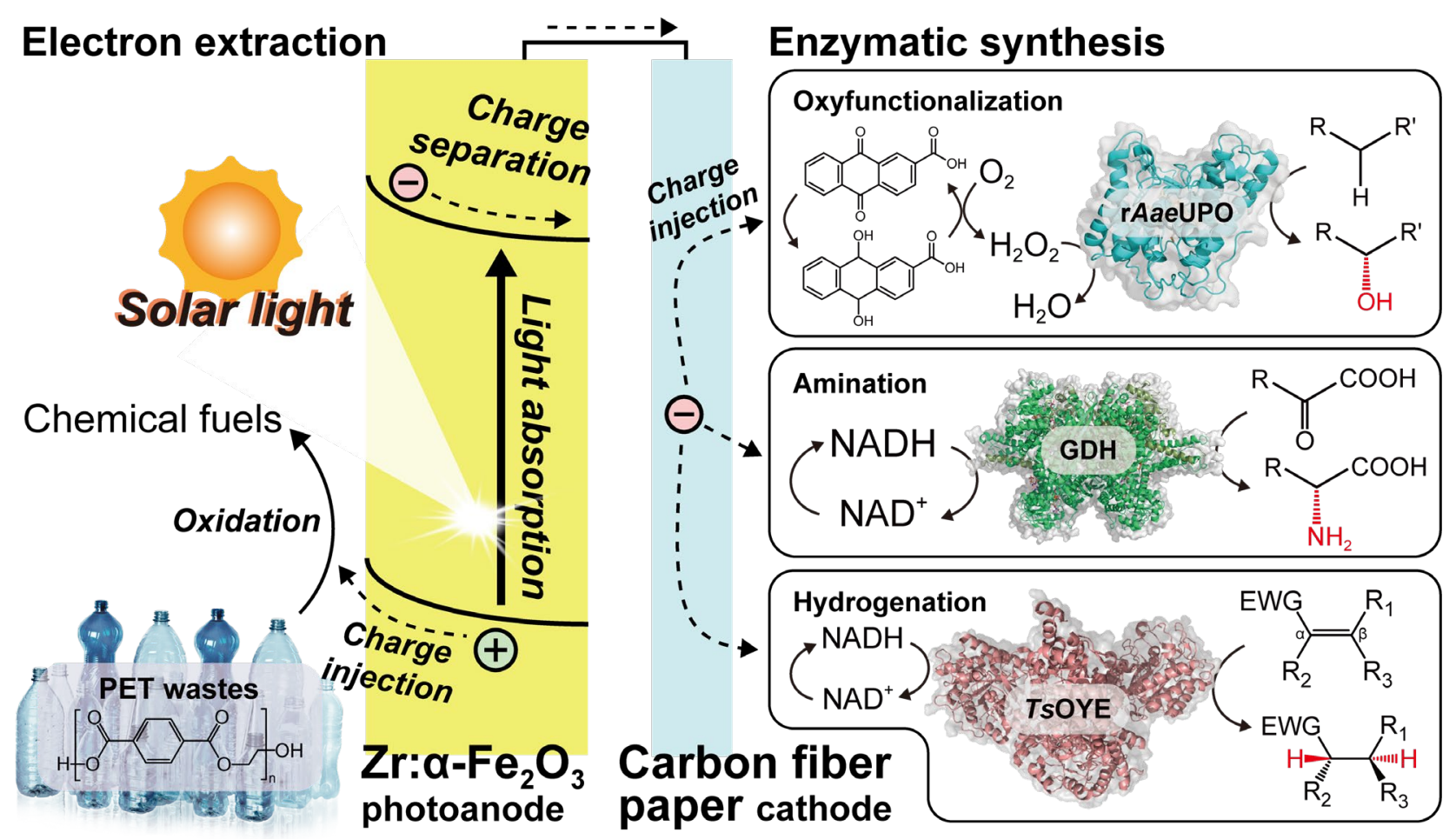

Fig. 1: Schematic diagram of solar-powered photoelectrochemical (PEC) biosynthetic reactions using nonrecyclable real-world poly(ethylene terephthalate) (PET) microplastics. A carbon fiber paper (CFP)-based cathodes reduce (i) $\mathrm{O}_{2}$ to $\mathrm{H}_{2} \mathrm{O}_{2}$ for biocatalytic oxyfunctionalization and (ii) $\mathrm{NAD}^{+}$to $1,4-\mathrm{NADH}$ for enzymatic amination and asymmetric hydrogenation. For the bioelectrocatalytic synthesis, a $\mathrm{Zr}$-doped hematite $\left(\mathrm{Zr}: \alpha-\mathrm{Fe}_{2} \mathrm{O}_{3}\right)$ photoanode extracts electrons from hydrolyzed PET solutions from post-consumer PET wastes of Starbucks and Coca-Cola companies. The biocatalytic PEC systems produce value-added compounds at both electrodes with excellent total turnover numbers of enzymes. 

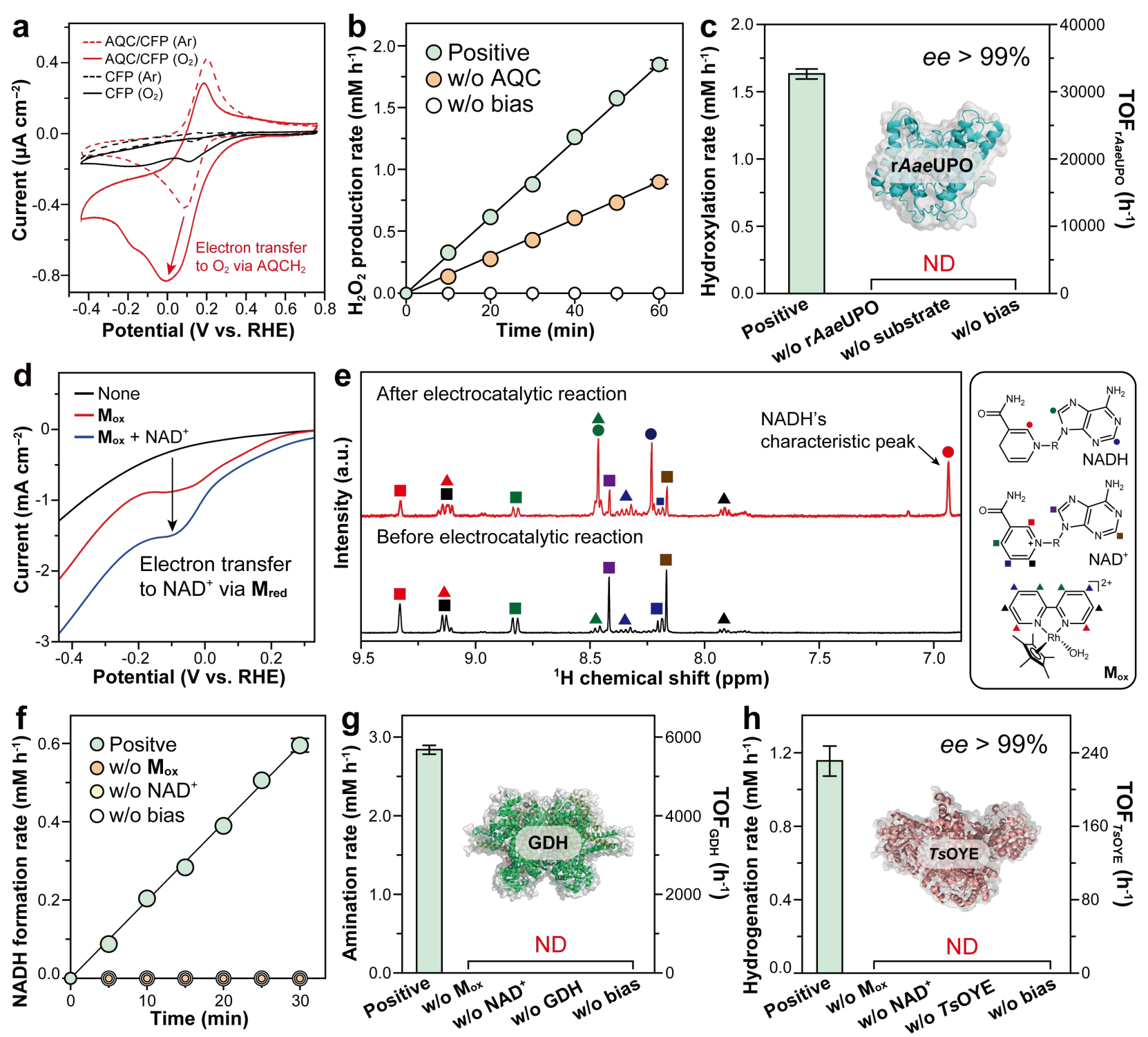

Fig. 2: Bioelectrocatalytic synthesis using CFP-based materials. (a) Cyclic voltammograms of $\mathrm{AQC} / \mathrm{CFP}$ and $\mathrm{CFP}$ cathodes under $\mathrm{O}_{2}$ or Ar-enriched environments. Electrolyte solution: a $\mathrm{KPi}$ buffer (100 mM, pH 6.0). (b) Time profiles of electrocatalytic production of $\mathrm{H}_{2} \mathrm{O}_{2}$. Electrolyte solution: an $\mathrm{O}_{2}$-rich KPi buffer $(100 \mathrm{mM}, \mathrm{pH}$ 6.0). (c) Biocatalytic electrochemical hydroxylation reaction using $\mathrm{AQC} / \mathrm{CFP}$ and $\mathrm{r}$ AaeUPO. (d) Linear sweep voltammograms for $\mathrm{NAD}^{+}$reduction. (e) ${ }^{1} \mathrm{H}$ nuclear magnetic resonance spectra before and after electrocatalytic reaction at -0.2 VRHE. Molecular structures of NADH, NAD ${ }^{+}$, and $\mathbf{M}_{\mathbf{0 x}}$ are shown in the right panel. Reaction time: $40 \mathrm{~min}$. (f) Electrochemical production of 1,4-NADH from $\mathrm{NAD}^{+}$using CFP cathode. (g) A series of control experiments in bioelectrochemical amination reaction using GDH. (h) Control experiments in enzymatic electrochemical hydrogenation reaction using $T_{s} \mathrm{OYE}$. Working electrode in (d-h): CFP. Geometrical surface areas of cathodes in (a-h): $1 \mathrm{~cm}^{2}$. Reaction temperature in (a-h): $303 \mathrm{~K}$. Applied bias in (b, c): $0.16 \mathrm{~V}_{\text {RHE. }}$ Applied bias in (e-h): $-0.2 \mathrm{~V}_{\text {RHE. }}$ Scan rate in $(\mathbf{a}, \mathbf{d}): 25 \mathrm{mV} \mathrm{s}^{-1}$. ND: not detected. Error bar: standard deviation $(n=3)$. 

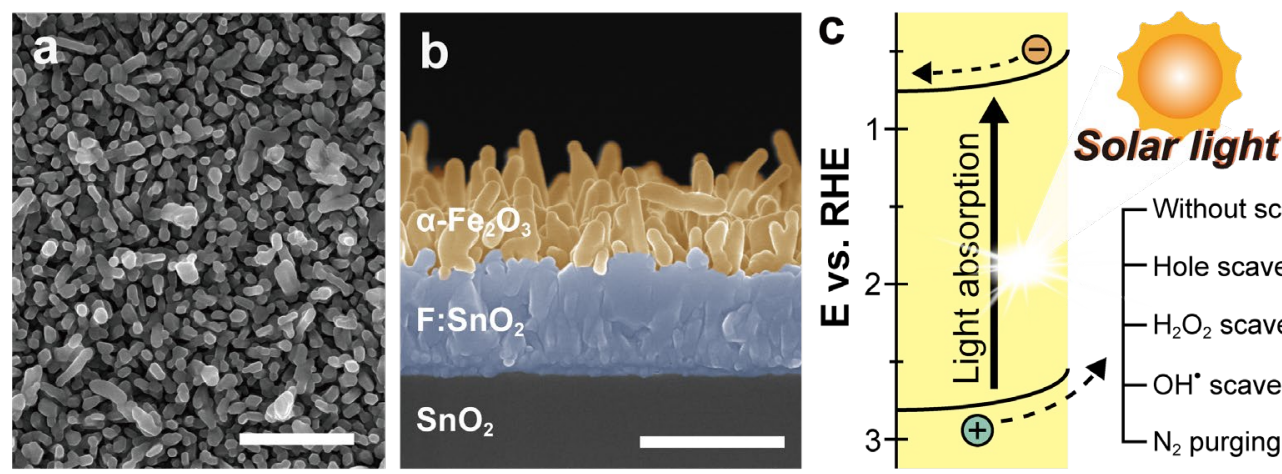

PEC oxidation
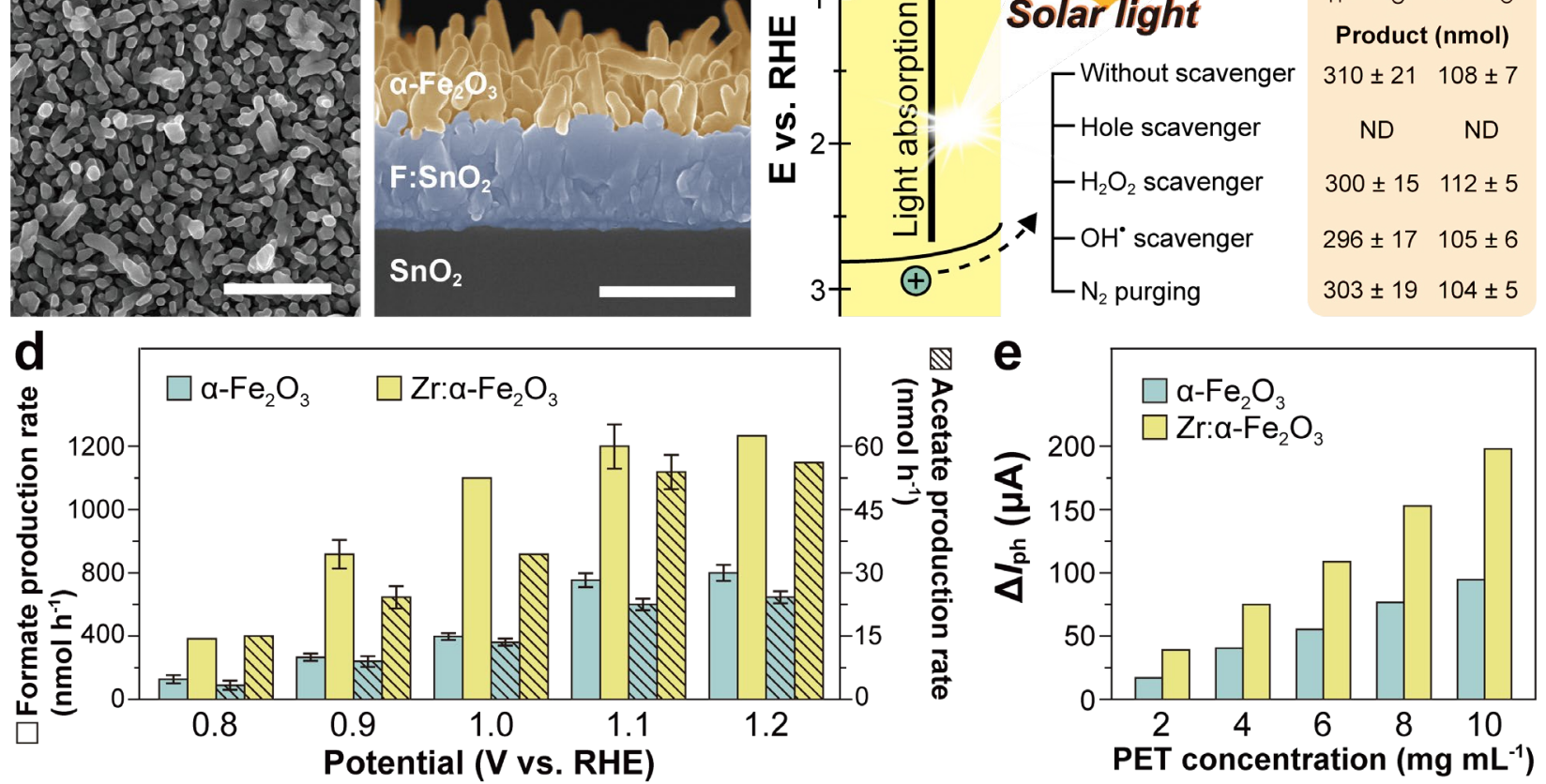

Fig. 3: PEC reformation of PET microplastics using $\mathrm{Fe}_{2} \mathrm{O}_{3}$-based photoanodes. (a) Plan-view SEM image of $\alpha-\mathrm{Fe}_{2} \mathrm{O}_{3}$ electrode. Scale bar: $1000 \mathrm{~nm}$. (b) Cross-sectional SEM image of the photoelectrode. Scale bar: $800 \mathrm{~nm}$. (c) Effects of various scavengers and $\mathrm{N}_{2}$ molecules on the PEC oxidation of PET microplastics for $12 \mathrm{~h}$ at $1.0 \mathrm{~V}$ RHE. Concentrations of scavengers: $300 \mathrm{mM} \mathrm{Na}_{2} \mathrm{SO}_{3}$ (hole scavenger), $300 \mathrm{mM}$ sodium pyruvate $\left(\mathrm{H}_{2} \mathrm{O}_{2}\right.$ scavenger), and $300 \mathrm{mM}$ tert-butyl alcohol $\left(\mathrm{OH}^{*}\right.$ radical scavenger). We separated photoanodic and cathodic sites using a salt bridge. (d) Potentialdependent production rates of formate and acetate driven by $\alpha-\mathrm{Fe}_{2} \mathrm{O}_{3}$ and $\mathrm{Zr}: \alpha-\mathrm{Fe}_{2} \mathrm{O}_{3}$ photoanodes. (e) Comparison of $\Delta I_{\mathrm{ph}}$ of the hematite-based photoanodes at $1.1 \mathrm{~V}_{\mathrm{RHE}} . \Delta I_{\mathrm{ph}} \equiv I_{p h}$ (specific concentration of PET) $-I_{p h}\left(0 \mathrm{mg} \mathrm{mL}^{-1} \mathrm{PET}\right)$. Light source in (c-e): solar simulator (AM 1.5G, 100 $\left.\mathrm{mW} \mathrm{cm}{ }^{-2}\right)$. Electrolyte solutions: (c) unpretreated PET solution (1 $\mathrm{mg} \mathrm{mL}^{-1}$ PET microplastics, $5 \mathrm{M}$ $\mathrm{NaOH}),(\mathbf{d})$ pretreated PET solution $\left(5 \mathrm{mg} \mathrm{mL}^{-1}\right.$ PET microplastics, $\left.5 \mathrm{M} \mathrm{NaOH}\right)$, and (e) pretreated PET solution (PET microplastics, $5 \mathrm{M} \mathrm{NaOH}$ ). Temperature in (c-e): $303 \mathrm{~K}$. ND: not detected. Error bar: standard deviation $(n=3)$. 

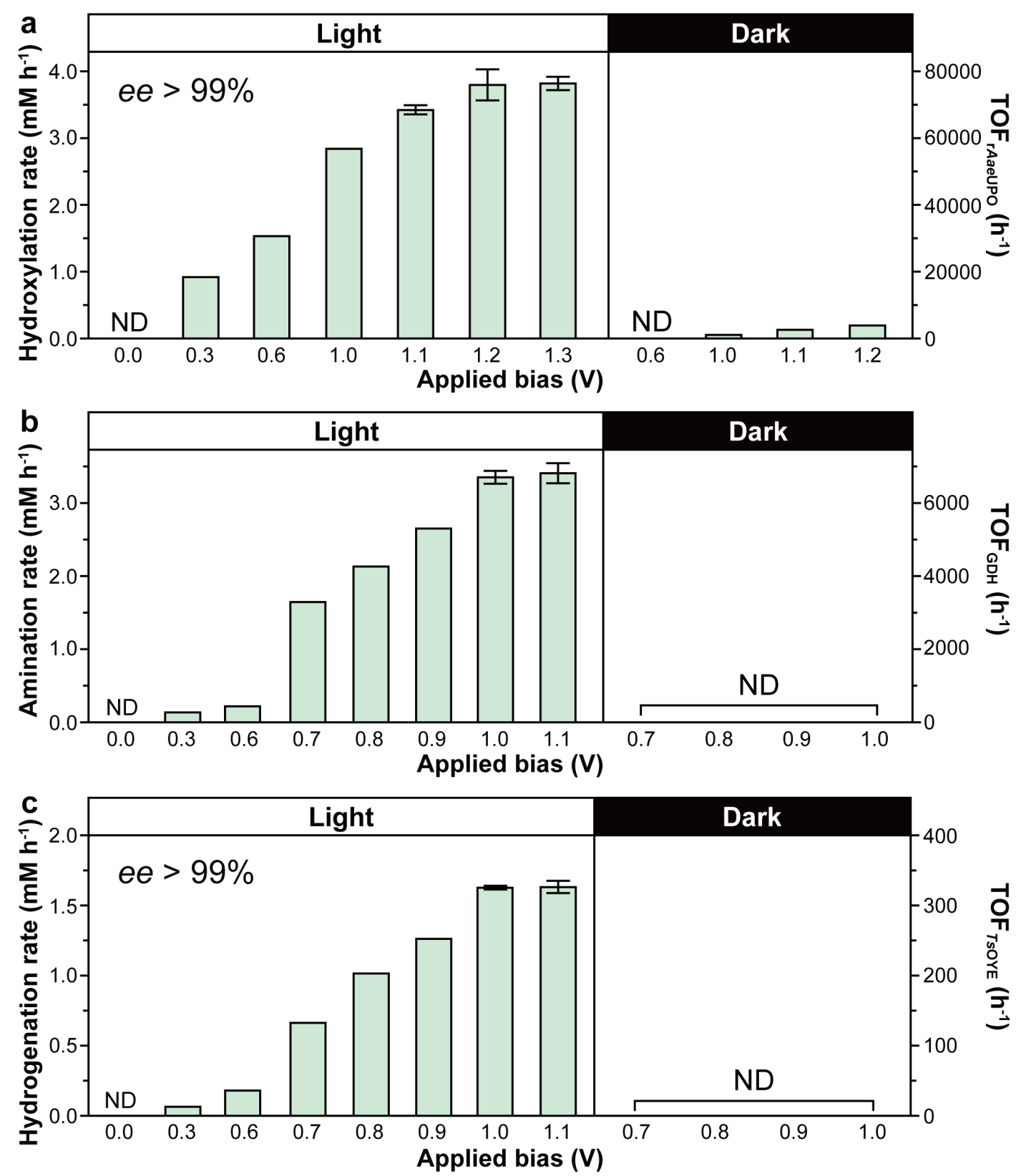

Fig. 4: Biocatalytic photoelectrochemical synthesis using real-world microplastics. Biasdependent enzymatic reactions driven by (a) $\mathrm{rAaeUPO}$, (b) GDH, and (c) TsOYE. Cathodic electrolyte in (a): $50 \mathrm{nM} \mathrm{rAaeUPO}$ and $16 \mathrm{mM}$ ethylbenzene in an $\mathrm{O}_{2}$-rich $\mathrm{KPi}$ buffer $(100 \mathrm{mM}, \mathrm{pH}$ 6.0). Cathodic electrolyte in (b): $500 \mathrm{nM} \mathrm{GDH}, 80 \mathrm{mM} \alpha$-ketoglutarate, $250 \mathrm{mM} \mathrm{NH} 4^{+}, 0.25 \mathrm{mM}$ $\mathbf{M}_{\mathbf{o x}}$, and $1 \mathrm{mM} \mathrm{NAD}^{+}$in an $\mathrm{O}_{2}$-depleted NaPi buffer (100 mM, pH 7.5). Cathodic electrolyte in (c): $5 \mu \mathrm{M}$ Ts OYE, $7 \mathrm{mM}$ 2-methyl-2-cyclohexen-1-one, $10 \mathrm{mM} \mathrm{CaCl}_{2}, 20 \mathrm{mM} \mathrm{NH}_{4}{ }^{+}, 0.25 \mathrm{mM} \mathrm{M}_{\text {ox }}$, and $1 \mathrm{mM} \mathrm{NAD}^{+}$in an $\mathrm{O}_{2}$-depleted TEOA-buffered solution $(100 \mathrm{mM}, \mathrm{pH} 7.5)$. Cathode in (a): AQC/CFP electrode. Cathodes in (b, c): CFP electrode. Anodic electrolyte in (a-c): pretreated PET solution (50 mg mL $\mathrm{mL}^{-1}$ PET microplastics, $5 \mathrm{M} \mathrm{NaOH}$ ) using Starbucks PET disposable cups. Light condition in (a-c): 1 sun (AM 1.5G, $100 \mathrm{~mW} \mathrm{~cm}^{-2}$ ). We irradiated solar light to the anodic site, not the cathodic site. Temperature: $303 \mathrm{~K}$. 

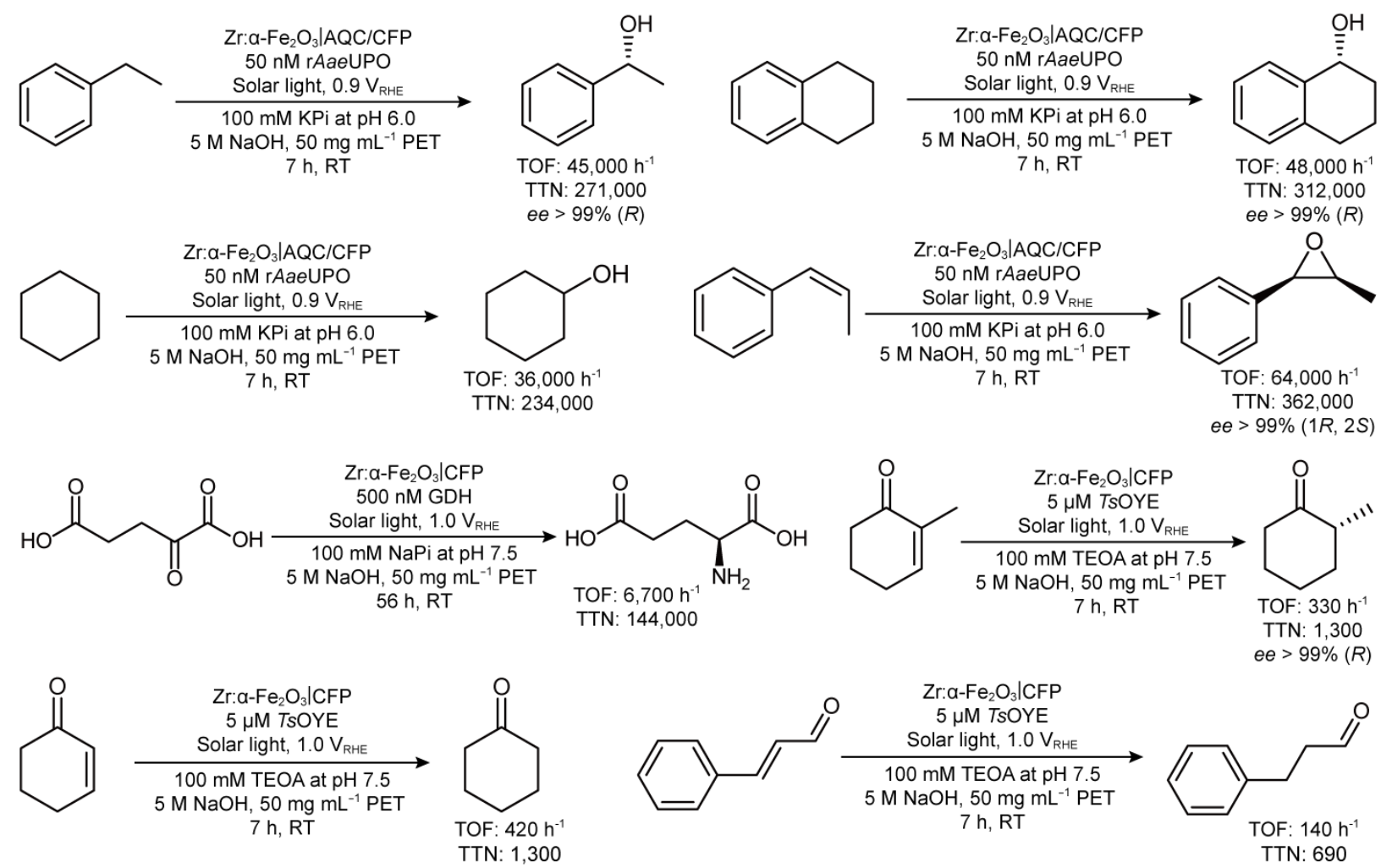

Fig. 5: Substrate scope of biocatalytic PEC reactions employing real-world PET microplastics. Cathodic electrolyte for $\mathrm{r} A a e \mathrm{UPO}$ reaction: $50 \mathrm{nM} \mathrm{r}$ AaeUPO and $16 \mathrm{mM}$ substrate in an $\mathrm{O}_{2}$-rich KPi buffer (100 mM, pH 6.0). Cathodic electrolyte for GDH reaction: $500 \mathrm{nM} \mathrm{GDH}, 80 \mathrm{mM} \alpha$ ketoglutarate, $250 \mathrm{mM} \mathrm{NH}_{4}^{+}, 0.25 \mathrm{mM} \mathrm{M}_{\mathbf{o x}}$, and $1 \mathrm{mM} \mathrm{NAD}^{+}$in an $\mathrm{O}_{2}$-depleted NaPi buffer (100 $\mathrm{mM}, \mathrm{pH}$ 7.5). Cathodic electrolyte for TsOYE catalysis: $5 \mu \mathrm{M}$ Ts OYE, $7 \mathrm{mM}$ substrate, $10 \mathrm{mM}$ $\mathrm{CaCl}_{2}, 20 \mathrm{mM} \mathrm{NH}_{4}{ }^{+}, 0.25 \mathrm{mM} \mathrm{M}_{\mathbf{o x}}$, and $1 \mathrm{mM} \mathrm{NAD}^{+}$in an $\mathrm{O}_{2}$-depleted TEOA-buffered solution (100 mM, pH 7.5). Anodic electrolyte: pretreated PET solution $\left(50 \mathrm{mg} \mathrm{mL}^{-1}\right.$ PET microplastics, 5 $\mathrm{M} \mathrm{NaOH}$ ) using Starbucks PET disposable cups. Light condition: 1 sun (AM 1.5G, $100 \mathrm{~mW} \mathrm{~cm}$ ch $^{-2}$. Temperature: $303 \mathrm{~K}$. 

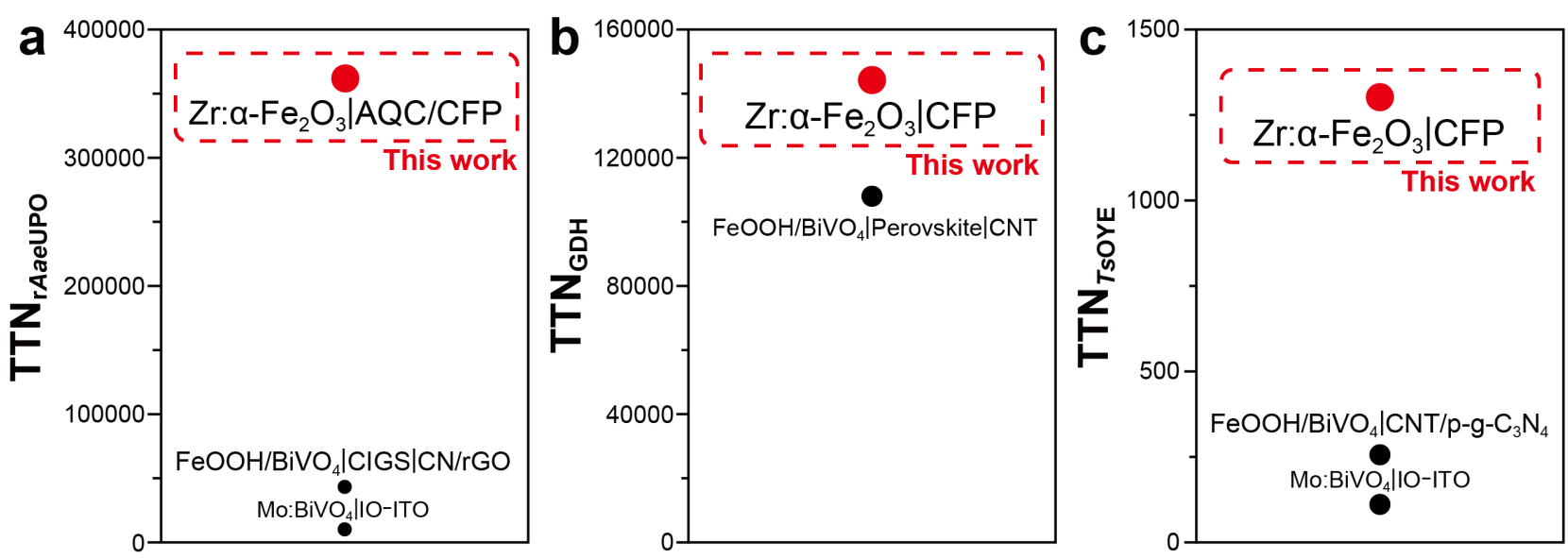

Fig. 6: Comparison of total turnover numbers (TTNs) of enzymes of state-of-the-art biocatalytic PEC systems. List of redox enzymes activated by PEC systems: (a) rAaeUPO, ${ }^{31,32}$ (b) $\mathrm{GDH},{ }^{13}$ and (c) $\mathrm{TsOYE}^{30,31}$. References: $\mathrm{FeOOH} / \mathrm{BiVO}_{4}|\mathrm{CIGS}| \mathrm{CN} / \mathrm{rGO},{ }^{32} \mathrm{Mo}: \mathrm{BiVO}_{4} \mid \mathrm{IO}-\mathrm{ITO},{ }^{31}$ $\mathrm{FeOOH} / \mathrm{BiVO}_{4} \mid$ Perovskite $\left|\mathrm{CNT},{ }^{13} \quad \mathrm{FeOOH} / \mathrm{BiVO}_{4}\right| \mathrm{CNT} / \mathrm{p}-\mathrm{g}-\mathrm{C}_{3} \mathrm{~N}_{4}{ }^{30}$. FeOOH/BiVO 4 : $\mathrm{FeOOH}-$ deposited $\mathrm{BiVO}_{4}$. CIGS: $\mathrm{Cu}(\mathrm{In}, \mathrm{Ga}) \mathrm{Se}_{2}$. $\mathrm{CN} / \mathrm{rGO}$ : graphitic carbon nitride/reduced graphene oxide hybrid. Mo:BiVO carbon nanotube. $\mathrm{CNT} / \mathrm{p}-\mathrm{g}-\mathrm{C}_{3} \mathrm{~N}_{4}$ : protonated graphitic carbon nitride/carbon nanotube hybrid. 